\title{
Fiducia: Algunos de sus rituales
}

\author{
Óscar Quezada M. (Universidad de Lima)
}

Recibido: 17/04/08

Aprobado: 25/05/08

RESUMEN: El hombre debe creer para poder dar sentido a eso que sabe. Existimos en las creencias, de ahí que la modalidad del "creer" sea aquella que sostiene en silencio a cada una de las demás modalidades haciendo que toda sociedad sea, fundamentalmente, fiducia. Este breve ensayo fija su atención en diversos fenómenos de repetición, fijación y ritualización, es decir, en los estereotipos puestos a disposición del sujeto para alimentar su programación discursiva. Estos elementos potencializados, se hallan en memoria; así, la creencia aparece como versión "tónica" e "intensiva" de esa potencialización, mientras el "tipo" y el "rito" son su versión "átona" y "extensiva". No es extraño, pues, que cuando la creencia se debilita sea recubierta por rituales automáticos.

Palabras clave: Creencia - ritualización - acontecimiento - valor - fiabilidad programa discursivo

\section{Trust: some of its rituals}

SuMMARY: Man must believe in order to make sense of that which he knows. We exist in believes, from which the modality of "believe" is that which maintains the silence of the other modalities making all of society, fundamentally, trust. This brief essay centers its attention on the repetition, fixation and ritualization phenomena, which means, the stereotypes used by the subject for incising its discursive programming. These empowerment elements are in the memory; this way, the believe appears in a "tonic" and "intensive" version of that empowerment, while the "type" and "ritual" are its "atonic" and "extensive" version. It's not strange, that, when the believe its weakened its covered by automatic rituals.

Key words: Believe - ritualization - event - value - trustworthiness - discursive program 


\section{Acontecimiento, amarra social}

$\boldsymbol{S}^{\mathrm{i}}$ el hombre supiese, el conocer $S$ perdería sentido. El atributo $s a-$ piens atribuido a homo no debe, pues, ser entendido como posesión sino, al revés, como privación y necesidad. El hombre es el ente que necesita saber $\mathrm{y}$, por eso, se esfuerza en lograrlo, se ocupa en conocer, hace lo que puede para saber, se informa. ${ }^{1}$

Pero con eso no basta. El hombre debe creer para poder dar sentido a eso que sabe. Señala Ortega y Gasset que las ideas se tienen y en las creencias se está. ${ }^{2}$ En efecto, las ideas son ocurrencias, pensamientos que tenemos y que, como tales se obtienen, se retienen, se mantienen, se sostienen o no. Las creencias, mientras tanto, son el continente mismo de nuestra vida, no remiten a lo que tenemos sino a lo que somos. No podemos vivir de aquellas ideas pero sí vivimos de estas creencias. La contraposición entre pensar en una cosa y contar con ella resulta decisiva para entender el sustrato mítico de la información como el acto de contar aquello con lo que se cuenta. Es en la fuerza de asunción de la creencia donde cualquier narración encuentra su especificidad como saber firme del que no se duda.
Pues bien, toda sociedad es fiducia. Valéry la asemeja a la inercia.

El orden social puede expresarse diciendo que toda sociedad organizada, ordenada, es, por eso mismo, conservadora de su fiducia, la cual corresponde a una economía de las fuerzas reales. ${ }^{3}$

Por eso, la repetición, la fijación, la ritualización producen tipos - $\mathrm{O}$, más bien, estereotipos y ritos-, disponibles en todo momento por parte del sujeto para alimentar su programación discursiva. Esto es más evidente aún en los rituales digitales de la automatización. Para Fontanille y Zilberberg se trata de

[...] unidades potencializadas, es decir, que no están ni virtualizadas ni actualizadas, porque han sido ya realizadas en los diferentes usos, y ni siquiera verdaderamente 'realizadas', ya que, de cierto modo, 'se hallan en memoria', a disposición de los sujetos de la enunciación. ${ }^{4}$

La inercia de la que habla Valéry se explica cuando la creencia es caracterizada como versión "tónica" e "intensiva" del modo potencializado, mien-

1 ORTEGA Y GASSET, J. Ideas y creencias, 1993, p. 14.

2 Ibídem, p. 23.

3 VALÉRY, P. Cahiers, 1974, p. 1526.

4 FONTANILLE, J. y C. ZILBERBERG. Tensión y significación, 2004, p. 240. 
tras el "tipo" y el "rito" son su versión "átona" y "extensiva". Una lógica de conmutación las vincula: cuando la creencia se debilita es recubierta por rituales automáticos; remitámonos nomás al modo dominante de vivir el cristianismo en Occidente.

Entonces, la solidez de los vínculos sociales depende del creer y de los rituales de la adhesión. Todo comienza, en alguna parte, por el 'acontecimiento' de una adhesión singular al discurso de alguien que orienta, nombra, narra, consagra. Para que el saber se abra paso hay que suspender la duda y dar crédito a un discurso y a su portador, destinador o remitente. Si $x$ se niega a creer a $y$ ataca la posibilidad misma de construir un saber. El creer es, pues, la amarra social. Como contraparte, la duda generalizada, acto de soberanía sin sumisión alguna, libera de todo compromiso. Se trata, en efecto, de un acto tan absoluto como vano: el sujeto se encierra en la pura virtualidad. Es inexpugnable porque jamás se ha comprometido a creer en algo. Su fuerte es no ser. El rechazo a creer entraña consecuencias semióticas: en primer lugar, la imposibilidad de constituir el saber; después, la imposibilidad de poner en marcha la narratividad; luego, a un nivel más profundo, este rechazo cuestiona la posibilidad misma de instaurar los valores y la significación. El destinador, en efecto, es la manifestación narrativa de la invariante, es decir, del punto fijo y estable de referencia, a partir del cual se explayan las significaciones; es, en suma, una manifestación del fundamento que garantiza los valores en circulación en la comunidad, que asegura el curso de los intercambios y la convertibilidad de los valores entre sí. Suprimir el destinador compromete la posibilidad misma de orientarse en el mundo y de atribuir una finalidad a la acción. Con él desaparecen el marco de referencia capaz de organizar el mundo y de dar sentido a la existencia. ${ }^{5}$

El "catastro" de los discursos creídos se relaciona con las cosas como si se tratase de un sistema de meridianos. Si nos desprendiéramos del meridiano 0 (Greenwich) daríamos vueltas en forma errática. No nos podríamos orientar ni llamar a las ciudades por su nombre. La navegación, entendida como praxis que deriva de un sistema de referencias topológicas, resultaría imposible en ese mundo. En efecto, si Lima está en Roma, entonces una manzana es una silla. ${ }^{6}$ Esta metáfora del meridiano 0 no es fortuita ni gratuita. El punto 0 es el fundamento del sistema de ubicación en el espacio y,

5 PIERRE, J. El creer y los inquietos bordes del saber, 1993, p. 5.

6 Ibídem, p. 2. 
como año 0, también en el tiempo. Su función es perfectamente comparable con la del destinador que proporciona los cimientos axiológicos al mundo.

Creer en ese destinador, fuente de los valores, es el acto por el que se inicia, localiza y consolida la existencia semiótica. Creer es crear los seres mismos del sentido. El creer funda la fiducia como vínculo. Crea las plazas de los 'jugadores'. Instaura la categoría destinador / destinatario; crea, instituye, la red de intercambios y proyecta, en términos polémicos, la categoría antidestinador / antidestinatario. No se trata, pues, de un objeto que circule entre los actantes de la comunicación sino del principio mismo que los instituye como tales.

Cabe decir, entonces, que el 'acontecimiento' de la fiducia circunscribe y controla simbólicamente la identidad de los actantes. Como vemos, por sí mismo, este 'acontecimiento' no tiene ninguna determinación salvo la de fundar toda posible determinación. Es, entonces, comparable al punto geométrico que ostenta el máximo de intensidad y el mínimo de extensión y que, por lo mismo, limita una línea de determinada longitud sin tener él mismo dimensiones. ${ }^{7}$ Cual axis mundi, es un lugar de fijación para las significaciones que se condensan a su contacto, sin hacer mella en su ser. Es el borne compacto y refractario de la significación.

El 'acontecimiento' hace, pues, resistencia a la significación pero, a la vez, la provoca. Es lo Otro de la significación. Si el 'acontecimiento' no fuera lo Otro de la significación entonces esta última lo atravesaría sin detenerse, erraría indefinidamente en búsqueda del obstáculo en el cual plasmarse. Para la significación, el 'acontecimiento' es impenetrable, le opone una superficie, como la tela al pincel, en la que puede inscribirse y desenvolver su forma. Constituye, pues, una condición de posibilidad de existencia de la significación. La significación 'precipita' sobre la superficie de un 'acontecimiento' que la resiste y la provoca. El mito sobreviene como gesto inaugural de este fenómeno.

Siendo la vida el misterio por antonomasia, el nacimiento es el 'acontecimiento' arbitrario (pudo no haberse dado) que se ubica en el fundamento del ser viviente. La muerte es su necesario correlato 'de salida'. Pero el nacimiento reconduce la vida a su propio umbral. La adosa al no-lugar que la precede y del que emerge. No-lugar al que, además, volverá por otro umbral correlativo. Nacimiento y muerte son, pues, 'acontecimientos', 'puntos' en los que la significación se sume, se condensa, pero también lugares en los

7 Ibídem, p. 10. 
que la significación encuentra una resistencia límite que la cuestiona e interroga.

\section{Intensidad / extensidad}

El valor de cualquier objeto está de algún modo $u$ otro condicionado por la relación entre, mínimo, dos sujetos. La fiducia, condición de posibilidad de los valores de verdad que circulan en el discurso, acoge las valencias -concebidas como 'condiciones del valor'-. Cualquiera que sea la modalidad analizada, desde el momento en que se la considera como un "valor" en circulación y no solo como un fragmento de competencia ni como un simple presupuesto del hacer, obedece a la correlación intensidad / extensidad. La valencia intensa, tónica, que se expresa en la fuerza de asunción del acto de creer, rige la capacidad de despliegue del saber expresada en una valencia extensa, difundida. La intensidad de una asunción rige a la extensión de un reconocimiento. El creer asigna un lugar de instauración y de despliegue al saber. Por ende, lo instala en un horizonte que limita su extensión. El saber, al no saber todo, al no saberse a sí mismo, encuentra en el creer un 'acontecimiento'.

A propósito de la correlación intensidad / extensidad, recuerda el adagio popular "Quien mucho abarca, poco aprieta", todo valor modal que aumenta en extensidad pierde en intensidad, en la medida en que esta se fragmenta y dispersa. Querer demasiadas cosas es quererlas más débilmente; un poder que se expande, tarde o temprano, es un poder que se debilita. En el caso del saber, si es considerado únicamente desde el ángulo de la competencia (acumulación de conocimientos o de saber-hacer), la correlación entre extensidad e intensidad es conversa: un saber amplio es un saber superior; pero si es considerado como un 'valor' susceptible sobre todo de fundar un proyecto de vida, de caracterizar la identidad de un sujeto, la correlación es inversa: el saber amplio se convierte en un saber superficial, mientras que la restricción del campo de conocimiento permitirá, por ejemplo, proyectar en él sistemas axiológicos como la 'especialización' o la 'erudición', con frecuencia menospreciadas como 'vanas' en nombre de la valencia de la extensidad.

El creer obedece también a la misma distinción: considerado simplemente necesario para el hacer, su extensión no daña en nada su eficacia. Si es sometido a una evaluación axiológica, la correlación también se invierte: creer en todo es ser un crédulo y, por consiguiente, es dar prueba de una fe devaluada, diluida o debilitada. La paradoja del crédulo consiste justamente en que no se le puede dar confianza, en la medida en que sus creencias no son selectivas. Pero inversamente, el que cree de modo muy intenso y selectivo al mismo tiempo, cae rápidamente en el sectarismo o en 
el fanatismo y recibirá reproches en nombre de la extensidad. ${ }^{8}$

Pero otra sentencia de Valéry nos indica que, en esto de la fiducia, por una cuestión de supervivencia, prevalecen las posiciones intermedias: “El mundo solo adquiere valor por los 'extremos', pero dura solamente por los 'medios'. Solo vale por los 'ultras', pero se conserva gracias a los 'moderados'" $^{\prime \prime}{ }^{9}$ Ese intervalo en el que el mundo se conserva, en el que tenemos que habérnosla con él, diseña una complejidad.

\section{Fiabilidad: Los 'materiales' de la complejidad}

Hay una indudable correspondencia de creencia y complejidad, pues, a final de cuentas, como sustenta Greimas, el creer es una actitud relativa y no categórica, en razón de lo cual, por ejemplo, el grado de creencia otorgado a un relato dado es muy variable. Por eso el creer suele manifestarse en forma de términos complejos: hay tendencia a creer y a no creer simultáneamente en un hecho o en un dicho. Ese lazo entre creencia y complejidad, entiende también Greimas, inclina esta última hacia el compromiso. ${ }^{10}$
Por su fuerza simbólica nos interesa reseñar la complejidad aspectual que concierne a la confianza en las cosas; esto es, a la fiabilidad; por ejemplo, de los materiales. Dicha fiabilidad se asocia, en ciertos casos, a la solidez: así, las fuerzas de cohesión tienden a perennizar y las fuerzas de dispersión tienden a destruir. Los términos de la categoría efímero vs durable aparecen como formas aspectuales y se refieren, en un orden netamente mítico, a cualidades concretas, sensibles. La fragilidad (que suspende lo durable y apunta a lo efimero, deixis de la precariedad) y lo resistente (que suspende lo efimero y apunta a lo durable, deixis de la solidez), términos subcontrarios, son siempre graduables. ${ }^{11}$

Esta demanda de fiabilidad de un "estado de cosas" deriva hacia una demanda de confianza en un "estado de alma". El "código mítico de materiales" aplica la fiabilidad de estos (exteroceptividad) a la duración de los lazos afectivos (interoceptividad): los materiales más precarios hacen referencia a una relación aún incipiente; de ahí que, en esta instancia temporal, tenemos bodas de papel, de cartón, de algodón. Gradualmente dejamos la deixis de la precariedad y pasamos a la

8 FONTANILLE, J. y C. ZILBERBERG. Op. cit., pp. 230-231.

9 VALÉRY, P. Op. cit., p. 1368.

10 GREIMAS, A. Des dieux et des hommes, 1985, pp. 22-23.

11 FONTANILLE, J. y C. ZILBERBERG. Op. cit., pp. 261-263. 
de la solidez, hasta que, en el extremo de lo durable, tenemos bodas de oro, de esmeralda, de diamante. No solo se ha crecido en solidez; se ha pasado, también, de la opacidad de lo precario al brillo y resplandor de lo sólido, de lo duro que dura. ${ }^{12}$

Entonces, la metáfora de la solidificación es decisiva para comprender el devenir de la fiducia. La solidez, promesa de permanencia, es apreciada como capacidad de mantener una sola forma y posición (extensidad), al precio de una fuerte cohesión interna (intensidad). La erosión de la fiducia, el crecimiento de la duda, aparece como una fluidez que debilita esa cohesión interna y promete una gran labilidad, una inconstancia de formas y posiciones en el tiempo y en el espacio. Por eso es que la competencia modal orientada a la realización del sujeto debe estar anclada en la fiducia de la que emergen los valores a los que apunta. Inhibiciones y fracasos, aparentemente inexplicables, provienen de la incapacidad para percibir la coherencia entre nuestra competencia y los valores a los que debemos acceder.

La "falta de seguridad" afecta a individuos pero también a grupos $\mathrm{y}$ sociedades. Raramente es una falta de competencia o un sentimiento de incompetencia. De otro lado, más allá de la extensión del sujeto, diremos que "tiene seguridad" si "cree en sí mismo", en su ser modal.

\section{Asumir / adherir}

En la línea de lo propuesto por Fontanille y Zilberberg, hemos señalado ya que el creer, como modalidad, corresponde al modo potencializado, primera etapa de la construcción de la competencia. En consecuencia, el sujeto, dispuesto a pasar al acto, percibe -o siente- su competencia como "eficiencia". Pero este acto de creer toma dos formas: la asunción -el sujeto asume su competencia como una eficiencia sentida "desde el interior", con toda "autonomía"-; y la adhesión -el sujeto adhiere a su competencia como a una eficiencia venida "del exterior", de modo heterónomo-. Los autores mencionados precisan que aquella, desde el punto de vista del alcance predicativo, es endógena, y desde el punto de vista tensivo, aperturante; esta, mientras tanto, desde esas mismas pertinencias, es una creencia exógena y clausurante. ${ }^{13} \mathrm{La}$

12 Es interesante recoger una versión anónima de este código mítico de bodas para dar cuenta de las oposiciones fuertes, extremas, y de las oposiciones graduables, intermedias: papel (1), algodón (2), piel o cartón (3), frutas y flores (4), madera (5), dulces y bombones (6), lana o cobre (7), bronce (8), cacharros o mimbres (9), hojalatería (10), acero (11), seda e hilo (12), encajes (13), marfil (14), cristal (15), porcelana (20), plata (25), perlas (30), coral (35), rubí (40), zafiro (45), oro (50), esmeralda (55), diamante (75).

13 FONTANILLE, J. y C. ZILBERBERG. Op. cit., p. 241. 
asunción abre el creer "desde adentro", la adhesión lo cierra "hacia fuera". Una da lugar a la "creencia en sí mismo"; la otra, a la "confianza en los demás". Lo social emerge como demasía, a saber, como lo de más que nos dan los demás. De ahí que símbolo sea aquello que tiene carácter añadido. ${ }^{14}$

Cabe decir, entonces, sobre todo con vistas a los rituales de la interacción mediática, que así como los cuerpos físicos están en movimiento, los cuerpos semióticos están en interpretación. Estar en interpretación es estar en tensión de creer y de hacer creer, de asumir y de crear adhesiones, desconfianzas, oposiciones y simpatías. ${ }^{15}$ Pero pensar que dicha tensión se resuelve exclusivamente en el establecimiento de verdades resulta parcial e ingenuo. Por cierto que esas verdades podrían, en caso de un consenso no amenazado por disenso alguno, esto es, de extraña unanimidad, llegar a ser una de sus dimensiones, pero entramados con el creer estar en verdad epistémico aparecen también el creer estar en lo bueno ético y el creer estar en lo agradable estético. Estos actos remiten al cuerpo sensible susceptible de ser conmovido por las estesias, por las aprehensiones impresivas, por las pasiones, por las emociones, es decir, por la eficiencia misma de la presencia del mundo o del otro. En suma, al cuerpo, interfaz propioceptiva operadora de semiosis, campo de tensiones en el que echa raíces cualquier discurso. Lo que está en juego no es una cuestión de junción ni de estados y transformaciones, sino una tensión fiduciaria dinamizada por las oscilaciones de la atracción, la repulsión y la indiferencia. Esas oscilaciones quedan manifiestas, por ejemplo, en las ansiosas digitaciones de ese dispositivo de interacción que es el mando a distancia, o sea, en las operaciones del zapping que definen al neoespectador televisivo. ${ }^{16}$ Ese sujeto no solo busca informarse eventualmente de verdades que lo orienten o construir una identidad por sucesivas o simultáneas adhesiones, quiere 'sentirse bien' habitando simulacros diversos. Un creer potencial lo preña aunque no sepa lo que quiere.

\section{Lucha de frases}

Tenemos ya un conjunto de consideraciones que apuntalan la tesis de Greimas de que la comunicación no es un simple intercambio de saber sino una empresa de persuasión y de interpretación en el interior de una estructura

14 HEIDEGGER, M. Einleitung in die Philosophie, 1996, p. 14.

15 COURTES, J. Análisis semiótico del discurso, 1997, p. 362.

16 PISCITELLI, A. Post-televisión, 1998. 
polémico-contractual". ${ }^{17}$ En la reflexión que presentaré a continuación pondré énfasis en un escenario polémico como campo de ofertas contractuales contradictorias a virtuales destinatarios de la información.

La llamada guerra de la información es, a final de cuentas, una guerra de la producción de sentido, una guerra de las significaciones y, por ende, de las interpretaciones divergentes y hasta contradictorias. En suma, una guerra axiológica que enfrenta modos incompatibles de construir la realidad. Porque la realidad es un objeto construido portador de significación. ${ }^{18}$ Objeto construido, y en permanente (re)construcción, desde posiciones confrontadas, polémicas; esto es, desde distintos puntos de vista. Para simplificar, una instancia toma posición desde la liberación de Iraq; la otra, desde su invasión. Entonces, pues, esta otra guerra en la que los contendientes pugnan por ganarse la conciencia de los destinatarios es algo muy serio, pues determina toda una "cosmovisión", o visión del mundo. Esta no es ni una simple consideración o contemplación de los acontecimientos, ni tampoco una suma del saber acerca de ellos. Una "cosmovisión" o visión del mundo es, siempre, una toma de posición (o postura), un posicionamiento en el que nos mantenemos por propia convicción, sea por una convicción que hemos desarrollado nosotros mismos por nuestra propia cuenta, o por una convicción que simplemente hemos adoptado por influencia de otro o imitando a otros, o a la que meramente nos ha acontecido ir a parar. ${ }^{19}$ Entonces nuestra cosmovisión es la fuerza motriz básica de nuestra acción y de toda nuestra existencia, aun en los casos en los que no apelamos expresamente a ella.

De acuerdo con la confianza o desconfianza que suscitan los discursos, se mueven los índices de una bolsa de valores del sentido que los devalúa o revalúa. Qué mayor poder que ese que conquista y somete con su espectáculo las conciencias. Hay que poner la información en el horizonte de la interacción comunicativa y recordar que viene empaquetada y codeterminada con instancias de opinión y de entretenimiento. Por citar un caso paradigmático, en el texto fílmico de Independence Day de Roland Emmerich (1996): el presidente de Estados

17 GREIMAS, A. y J. COURTES. Semiótica. Diccionario razonado de la teoría del lenguaje. Tomo 1, 1982, pp. 73-74.

18 GREIMAS, A. y J. COURTES. Semiótica. Diccionario razonado de la teoría del lenguaje. Tomo 2, 1991, p. 214.

19 HEIDEGGER, M. Introducción a la filosofía, 2001, p. 247. 
Unidos de Norteamérica se convierte en intrépido piloto de guerra que enfrenta y derrota a las fuerzas de invasión extraterrestres. $\mathrm{O}$, en el mundo de la opinión, los portavoces influyentes que toman partido y tiñen la información o la opinión a su gusto. ${ }^{20}$

Retomando la dinámica de la información, nadie duda de que los "acontecimientos reales" sean la materia prima de esa construcción llamada "realidad", es decir, de que están supuestos por esta. Pero también es cierto que nadie tiene acceso directo, absoluto, total e inmediato a "lo real". Los discursos informativos reciben su valor del contacto con lo que no es discurso, esto es, del contacto con lo real que se les resiste, que se les sustrae pero que, a la vez, los atrae. Ocurre como si el lenguaje en acto fuese la interfaz real / realidad.

Entonces "lo real" se hace o deviene "realidad" gracias, entre otras cosas, a la información significante (o significativa); de ahí que el drama del periodista no tiene tanto que ver con el conocimiento de lo real (que siempre es inagotable, incompleto e imperfecto) como con la determinación de lo que considera "realidad", esto es, de lo que da más menos sentido a la vida de sus destinatarios.

En otros términos, el drama del periodista es más afectivo y ético que cognitivo. La mayor o menor suscepti- bilidad de los periodistas frente a la eficiencia de los aparatos de propaganda de las partes en conflicto, es decir, a los partes de las partes, depende del grado de solidez con el que han cerrado un pacto de adhesión y, como correlato, del grado de libertad que tienen para abrirse a otros modos de asumir los acontecimientos. Lo que está en juego en esta lucha de frases de la información, más aún ante un escenario real de rivalidad o de guerra, es el parecer verdad o, para ser más exactos, el hacer parecer verdad y, en especial, la confianza que suscitan o no las fuentes de información en sus blancos.

En efecto, todo hacer parecer verdad es hacer creer verdad. Recordemos que parecer tiene dos acepciones: el aparecer de los acontecimientos (esto parece una tragedia) y el creer de las personas (esto me parece una tragedia). Por un lado, la construcción más o menos extensa de las evidencias, esto es, de los 'estados de cosas' que se dan a ver. Por otro lado, la adhesión más o menos intensa correspondiente a los 'estados de alma' de los destinatarios intérpretes de los mensajes. Pues lo que se da a ver, a la vez, se da a creer. Si todo fuese cuestión de dar a ver, la guerra de la información la ganarían quienes invierten más recursos financieros en propaganda. Pero las cosas no son tan simples.

20 LANDOWSKI, E. La sociedad figurada. Ensayos de sociosemiótica, 1993, pp. 21-57. 
No es lo mismo creer en lo que dice alguien, o sea, creer en el contenido de la información -lo verosímil-, que creer al que dice algo, es decir, creer en la fuente de la información -la credibilidad-. ${ }^{21}$ En la práctica, el régimen de la evidencia es el de una implicación muy simple: si veo que las tropas de la coalición se acercan a Bagdad, entonces, creo, en efecto, que se acercan. $\mathrm{O}$, en negativo, si no veo que hayan capturado a Osama Bin Laden, entonces, no creo que hayan capturado a Osama Bin Laden. En el esquema tensivo, se trata de una correlación conversa entre la extensidad del ver y la intensidad del creer: a más ver más creer; a menos ver menos creer. ${ }^{22}$

Pero la creencia, esto es, el régimen de la confianza, tiene otra lógica. Es una lógica concesiva que apunta más al acontecimiento del afecto, del 'estado de alma'; esto es, a la simpatía o a la antipatía que suscitan las fuentes. Así, por más verdad que parezca lo que alguien informa, a mí no me parece cierto. Puedo no creerle porque, de algún modo, ya sé quién es. Una de las más célebres pancartas recogidas de alguna de las manifestaciones contra la guerra en Iraq rezaba: "No creemos en las imágenes, no nos están mos- trando la realidad". Esto se traduce como: no creo en eso aunque lo vea.

Igual a la inversa, puedo creer en alguien por el mero hecho de que le tengo confianza aunque su discurso no parezca tan verosímil: creo en eso aunque no lo vea. En ese sentido, "creo que debe haber más víctimas aunque no me las enseñen, aunque no las vea. Esto es un horror, yo lo sé." En el esquema tensivo, se trata de una correlación inversa entre la extensidad del ver y la intensidad del creer: a más ver, menos creer; a menos ver, más creer.

Un bombardeo puede aparecer, 'desde arriba', desde las cabinas de los aviones o desde el satélite, como un inocuo fuego artificial. Y también puede aparecer, 'desde abajo', desde las calles mismas de la ciudad bombardeada, como una sangrienta masacre. Cabe preguntar: ¿qué se da a ver para inducir al creer? No solo se trata de constatar cómo en el suelo del hacer creer está el hacer sentir. Los hilos se tejen en otras direcciones: si, por praxis enunciativa, esto es, por el modo como ha asumido el contexto de la información, el destinatario cree que se están bombardeando posiciones militares enemigas y escucha, en sincronía con la imagen visual de zonas de Bagdad en

21 Ibídem, p. 204.

22 FONTANILLE, J. “La caída de Lucifer. El fin de las evidencias y el advenimiento de la retórica", en QUEZADA, O. (ed.). Fronteras de la semiótica. Homenaje a Desiderio Blanco, 1999 , p. 35. 
llamas, la voz de un narrador de CNN que le habla de 'explosiones' y no de 'bombardeos', puede verse inducido a confiar en esa 'evidencia'. En efecto, la coartada tecnomilitar del discurso de medios como $\mathrm{CNN}$, que a veces parecía la agencia de noticias del Pentágono, presentaba los bombardeos aéreos como operaciones quirúrgicas, asépticas, perfectas, dirigidas solo a objetivos militares. Apelando al imaginario del video-game, ocultaba la posible, y bastante creíble, dimensión criminal del acontecimiento. No olvidemos que las imágenes 'bélicas' de la CNN en la guerra del Golfo Pérsico, en 1991, ya presentaban la operación militar como una especie de guerra virtual sin pérdidas de vidas humanas.

No obstante, una praxis enunciativa ya no tan contractual sino más bien polémica puede llevar a la suspicacia y a la desconfianza en esa supuesta 'evidencia'. Desde Al-Jazeera, algo que los occidentales no tenían previsto, la pertinencia de la puesta en discurso del acontecimiento ya no es tecnomilitar, es humana, urbana; en suma, civil.

La estrategia del video-game se ha desmoronado. Estamos en el punto de vista del "otro lado"... Las cadenas occidentales están obligadas, les guste o no, a abrir su línea informativa; podemos ver entonces más variedad de esas "otras" imágenes. Sobre todo, de imágenes trágicas de destrucción, incertidumbre, muerte, desesperación y desolación.

La puesta en escena periodística que "acompaña" a la poderosa coalición asume, pues, decididamente, la pertinencia militar. Otorga respetabilidad tecnológica y científica a la “operación". Mientras tanto, la puesta en escena que "acompaña" a la víctima súbitamente descubierta asume, sin más, la pertinencia del civil que vive el horror no solo en las ciudades, también en pequeños pueblos y en zonas desérticas. No es lo mismo, pues, ver "desde arriba" que "desde abajo", con todas las connotaciones que estos términos puedan tener.

\section{Concesión / implicación}

El "o...o", forma implicativa y silogística, plantea un requerimiento: de dos versiones una. Pero la concesión da de baja su mutuo rechazo, deja de lado esa recíproca abyección, remonta el "o...o" hacia el " $y \ldots y$ ". Así pues, aunque la doxa disjunte las magnitudes de sentido, la concesión afirma su coexistencia. Cada versión puede tener algo de verdad: baja la intensidad de la asunción $y$, en términos de extensidad, la verdad se parte, se divide, en verdades.

No es casual que lo sagrado, por ejemplo, aparezca al mismo tiempo, como lo lejano y lo cercano, como lo digno de confianza y protector, pero 
al mismo tiempo, como lo pavoroso e inaccesible, como mysterium tremendum y como mysterium fascinosum. ${ }^{23}$ Ahí donde la implicación se contenta con enunciados tan "razonables" como decepcionantes: lo cercano es cercano, lo lejano es lejano; la concesión afirma la doble necesidad de alejamiento de los próximos y de proximidad de los lejanos: lo cercano es lejano, lo lejano es cercano.

En ese sentido, si consideramos el motivo ético del perdón diremos que el perdón verdadero tiene por objeto lo imperdonable en la medida en que lo perdonable conlleva ya el perdón. Entonces, el mérito de este acto no está, por ejemplo, en perdonar lo perdonable ("te perdono porque lo que has hecho es perdonable") sino en lo perdonar lo imperdonable ("te perdono aunque lo que has hecho sea imperdonable"). Ese último enunciado, lapidario, cataliza una estructura concesiva y exclamativa: "a pesar de que el acto que has cometido es absolutamente imperdonable, iyo te perdono!". Los méritos del 'sublime' y tónico perdón de lo imperdonable no tienen comparación con el 'mediocre' y átono perdón de lo perdonable. ${ }^{24}$

Entonces, de acuerdo con la sistemática propuesta por Zilberberg, ${ }^{25}$ las estructuras y operaciones de la fiducia se obtienen por composición del verbo director creer, bajo formas conjuntivas y disyuntivas: creer y no creer, con el objeto potencializado de la creencia en un universo de discurso dado: lo creíble y lo increíble. "Mecánicamente", se obtienen cuatro sintagmas elementales que permiten a los sujetos elegir una de las combinaciones, la cual, si es asumida, se convertirá en un estilo fiducial: los sintagmas implicativos serían, con sus denominaciones: [creer lo creíble $\approx$ la creencia], [no creer lo increíble $\approx$ el escepticismo]; los sintagmas concesivos: [creer lo increíble $\approx$ la fé], [no creer lo creíble $\approx$ la incredulidad].

En relación con nuestra lucha de frases, las preguntas caen por su propio peso: ¿cómo así una versión aparece más creíble que la otra? ¿En qué momento dudamos de las 'evidencias' y retiramos confianza a la versión dominante?, ¿lo increíble puede devenir creíble y lo creíble increíble? Una clave de respuesta a estas preguntas puede estar en la tesis de la fiducia como complejidad hecha de tensiones que suelen convertir los límites en grados.

La implicación, inmanente a la 'progresividad', a la silogística, participa

23 CASSIRER, E. Filosofía de las formas simbólicas. Tomo 2. El pensamiento mítico, 1998, p. 111.

24 ZILBERBERG, C. Semiótica tensiva, 2005, p. 79.

25 Ibídem, p. 427. 
en los procedimientos de 'llegar a'; pero, más allá de la mera lógica, puede articularse también por la constancia y solidez que va cobrando una determinada 'línea informativa' dominante. Mientras tanto, la concesión se halla en la base del acontecimiento, de la sorpresa, de la 'superlatividad' súbita -sea providencial o fatal-: emerge repentina desde el horizonte del mundo 'ideológicamente' instalado otra línea informativa que, contra todas las 'evidencias', contradice la línea anterior. En este último estilo, el "aunque" hace fracasar al "porque" esperado. Para exagerar con la metáfora de los materiales: el papel se vuelve diamante... y viceversa.

Señala Zilberberg que la importancia de la concesión es solidaria de la tensión propia de los modos de eficiencia, es decir, de la tensión existencial entre el 'sobrevenir', sinónimo de despliegue para el sujeto y el 'llegar a' [parvenir], el cual, si no interviene precisamente algún 'sobrevenir' como contraprograma inoportuno, valida la confianza que el sujeto otorga a sus propias capacidades y a los recursos de que dispone.

En efecto, el éxito del 'llegar a' conforta al sujeto en la convicción de que el mundo es precisamente 'su' mundo, de que el cálculo y la previsión tienen en él su lugar, de que su doxa es correcta y funciona (pues en lo creíble se halla presupuesto un creer anterior); mientras que la irrupción del 'sobrevenir' viene a recordarle que una 'inquietante extrañeza' puede manifestarse de improviso, como un reverso que se invirtiese. ${ }^{26}$ Parece, pues, que la dimensión fiduciaria es la única capaz de exhibir el funcionamiento semiótico de la concesión, apertura misma, por ir a un ejemplo paradigmático, de todos los universos de ficción y de todos los simulacros más o menos espectaculares de la interacción digital: "aunque sepa que esas películas o esas tramas lúdicas son 'de mentira' las veo o las opero como si fuesen verdad, decido creérmelas, habitarlas". Queda de manifiesto la tesis de Ortega y Gasset en orden a tratar el creer como continente de todos y cada uno de los contenidos del conocimiento... y del afecto.

\section{Bibliografía}

CASSIRER, E. Philosophie der symbolischen Formen. Zweiter Teil, Das Mythische Denken. Darmstadt: Wissenschaftliche Buchgesellachaft, 1964. [Traducción al español: Filosofía de las formas simbólicas. Segundo tomo. El pensamiento mítico. México: Fondo de Cultura Económica, 1998 [1971].] 
COURTÉS, J. Analyse sémiotique du discours. De l'enoncé a l'énonciation. París: Hachette, 1991. [Traducción al español: Análisis semiótico del discurso. Madrid: Gredos, 1997.]

FONTANILLE, J. "La caída de Lucifer. El fin de las evidencias y el advenimiento de la retórica", en QUEZADA, O. (ed.). Fronteras de la semiótica. Homenaje a Desiderio Blanco. Lima: Universidad de Lima/ Fondo de Cultura Económica, 1999.

FONTANILLE, J. y C. ZILBERBERG. Tension et signification. Lieja: Pierre Mardaga, 1998. [Traducción al español: Tensión y significación. Lima: Universidad de Lima, 2004.]

GREIMAS, A. Des dieux et des hommes. París: Presses Universitaires de France, 1985.

GREIMAS, A. y J. COURTÉS. Sémiotique. Dictionnaire raisonné de la théorie du langage. París: Hachette, 1979, 1986. [Traducción al español: Semiótica. Diccionario razonado de la teoría del lenguaje. Tomo 1 (1982); tomo 2 (1991). Madrid: Gredos.]

HEIDEGGER, M. Einleitung in die Philosophie. Frankfurt am Main: Vittorio Klosterman, 1996. [Traducción al español: Introducción a la filosofía. Valencia: Frónesis-Cátedra, 2001.]

_. Eine Sammlung von Vorträgen. Frankfurt: Vittorio Klosterman, 1984. [Traducción al español: Caminos de bosque. Madrid: Alianza Editorial, 1996.]

LANDOWSKI, E. La sociéte réfléchie. París: Editions Du Seuil, 1989. [Traducción al español: La sociedad figurada. Ensayos de sociosemiótica. México: Fondo de Cultura Económica, 1993.]

ORTEGA Y GASSET, J. Ideas y creencias. Madrid: Alianza Editorial, 1993 [1986].

PIERRE, J. "Le croire et la bordure inquiète du savoir", en PANIER, L. (éd.). Le temps de la lecture. París: Les éditions du Cerf, 1993. [Traducción al español: El creer y los inquietos bordes del saber. Lima: Universidad de Lima, 1993.

PISCITELLI, A. Post-televisión. Buenos Aires: Paidós, 1998.

VALÉRY, P. Cahiers. París: Gallimard, col. La Pléiade, 1974.

ZILBERBERG, C. Semiótica tensiva. Traducción al español de Desiderio Blanco. Lima: Universidad de Lima, 2005. 